\title{
Adoptive transfer method to study platelet function in mouse models of disease
}

\author{
Wolfgang Bergmeier ${ }^{1,2}$ and Yacine Boulaftali ${ }^{2}$ \\ 1Department of Biochemistry/Biophysics, University of North Carolina at Chapel Hill, Chapel Hill, \\ NC, USA
}

${ }^{2}$ McAllister Heart Institute, University of North Carolina at Chapel Hill, Chapel Hill, NC, USA

\begin{abstract}
Platelets play an important role in many physiological and pathological situations. However, the molecular mechanisms by which platelets contribute to health and disease are often ill-defined. One of the limiting factors to these studies is a fast but reliable method to generate animals with platelet-specific signaling defects. We here review recent approaches to establish an adoptive platelet transfer model in mice.
\end{abstract}

\section{Introduction}

\begin{abstract}
Studies in animal models of disease identified a central role for platelets in various physiological and pathological situations, including hemostasis and thrombosis, angiogenesis, vascular integrity, development, immunity, ischemia-reperfusion injury, arthritis, atherosclerotic lesion development, tumor metastasis, and sepsis [1,2]. While studies on the contribution of platelets to developmental processes depend on the availability of genetically modified mice, experimentally induced severe thrombocytopenia is the most frequently used model system to identify whether platelets are critical in a particular pathophysiological process. For example, studies in animals depleted of virtually all circulating platelets provided strong evidence for a critical contribution of these cells to angiogenesis $[3,4]$, vascular integrity [5,6], or tumor metastasis [7,8]. Clarification of the molecular mechanisms by which platelets contribute to health and disease, however, is much more complicated as genetic deletion or chemical inhibition of platelet signaling molecules or vasoactive/ immune-modulatory mediators generally also affects cells of the innate and adaptive immune response as well as the vessel wall. Deletion of genes specifically in the megakaryocyte/platelet-lineage with the loxP/PF4-Cre system has been instrumental to
\end{abstract}

(c) 2014 Elsevier Ltd. All rights reserved.

Corresponding author: Wolfgang Bergmeier, PhD, University of North Carolina At Chapel Hill, 98 Manning Drive, Campus box 7035, North Carolina, 27599, bergmeie@email.unc.edu.

Publisher's Disclaimer: This is a PDF file of an unedited manuscript that has been accepted for publication. As a service to our customers we are providing this early version of the manuscript. The manuscript will undergo copyediting, typesetting, and review of the resulting proof before it is published in its final citable form. Please note that during the production process errors may be discovered which could affect the content, and all legal disclaimers that apply to the journal pertain.

Conflict of interest statement

The authors declare no conflict of interest. 
overcome this limitation [9]. The use of the Cre-Lox system, however, is limited due to the costs and the time associated with the generation, breeding, and maintenance of these mice. Thus, an alternative, more efficient method to generate mice with platelet-specific signaling defects is required to uncover the molecular mechanisms by which platelets contribute to the above discussed patho-physiological situations.

\section{Genetic, chemical, and antibody-based approaches to induce thrombocytopenia}

For many years, scientists have tried to generate mice with very low platelet counts that could be used for adoptive transfer studies with genetically modified or inhibitor-treated platelets (Table 1). Genetic approaches have led to the generation of mice with very low platelet counts. For example, peripheral platelet counts in mice lacking the thrombopoietin receptor c-Mpl are reduced by $\sim 90 \%$ compared to controls due to a defect in megakaryocytopoieses [10]. However, the remaining platelets are fully functional and genetic deletion of c-Mpl also affects other hematopoietic progenitor cells. Genetic deficiency in the transcription factor p47 NF-E2 [11,12] strongly impairs thrombopoiesis in mice. The resulting severe thrombocytopenia (mice are virtually free of circulating platelets) leads to perinatal lethality due to excessive hemorrhage. In addition, p47 NF-E2 knockout mice show several red blood cell defects, including anisocytosis and hypochromia. Thus, genetic models of thrombocytopenia are of limited use for adoptive transfer studies. Thrombocytopenia in mice can also be induced by chemotherapeutic agents such as 1,4butanediol dimethanesulfonate (Busulfan) [13] or Abt-737, a small molecule inhibitor that targets pro-survival Bcl-2 proteins [14,15]. The cytotoxic effects of both compounds, however, are not limited to the megakaryocyte/platelet lineage. Busulfan-treated mice also show marked leukopenia and thus should not be used for studying inflammation in mice. Abt-737 is less cytotoxic to leukocytes, likely due to the fact that these cells express another pro-survival relative, myeloid cell leukemia-1 (Mcl-1), which is insensitive to Abt-737 [16]. While busulfan affects megakaryocyte maturation and platelet generation, Abt-737 causes apoptosis and clearance of circulating platelets and therefore does not allow for the adoptive transfer of donor platelets. Cytotoxic antibodies directed towards platelet-specific antigens do not affect peripheral erythrocyte or leukocyte counts $[13,17]$ and may therefore be considered the only method to completely eliminate circulating platelets without affecting other blood cell populations. However, there are two major problems associated with this method. First, rapid antibody-induced clearance of virtually all circulating platelets can lead to anaphylaxis-like reactions and severe vascular damage in mice [18-20]. These complications are well-documented for antibodies to aII $\beta \beta 3$, the main integrin receptor expressed on platelets. In contrast, antibody targeting of the GPIba subunit of the von Willebrand receptor complex leads to virtually complete thrombocytopenia without vascular damage in mice. Detailed mechanistic studies demonstrated that anti-GPIba antibodies induce thrombocytopenia by a unique mechanism that is independent of $\mathrm{Fc}$ receptormediated clearance of platelets by the reticuloendothelial system. The second major drawback of this method is the fact that thrombocytopenia depends on circulating cytotoxic antibodies. Consequently, transfusion of donor platelets into these thrombocytopenic mice is not possible as long as the antibodies remain in circulation. Thus, successful adoptive 
transfer of platelets requires a method where (1) thrombocytopenia is induced by an antiGPIba antibody-like mechanism and (2) circulating antibodies are not cytotoxic towards the transfused platelets.

\section{A novel, antibody-based method for the adoptive transfer of platelets}

Both requirements can be met when thrombocytopenia is induced by antibodies against human IL4Ra in transgenic mice expressing a chimeric hIL4Ra/GPIba protein instead of GPIba on the platelet surface [17]. In these mice, the extracellular domain of GPIba is replaced by the extracellular domain of hIL4R [21]. Infusion of anti-hIL4R antibodies into these animals leads to rapid, severe thrombocytopenia without signs of an anaphylaxis-like response, suggesting that these antibodies induce platelet clearance by a mechanism similar to that described for anti-GPIba antibodies. Importantly, transfusion of WT platelets lead to a dose-dependent increase of the peripheral platelet count in thrombocytopenic hIL4Ra/ GPIba mice, and the transfused platelets showed normal hemostatic function when tested in various models of thrombosis and inflammation [17]. To validate the power of this approach, platelets with defects in immunoreceptor tyrosine-based activation motif (ITAM) or G protein-coupled receptor (GPCR) signaling were tested for their ability to maintain vascular integrity in inflammation. To eliminate signaling via the main GPCR receptors, mouse platelets were isolated from Par4-/- mice treated with clopidogrel (an irreversible inhibitor of P2Y12), followed by incubation with aspirin to irreversibly prevent cyclooxygenase-mediated thromboxane $\mathrm{A} 2$ generation and platelet activation by thromboxane receptors. Before transfusion into thrombocytopenic hIL4Ra/GPIba-tg mice, these cells were washed to remove free inhibitor. It is important to remember that aspirin is an anti-inflammatory drug and expression of both Par4 and P2Y12 is not specific to platelets. Thus, the adoptive transfer model provided a unique and powerful tool to generate mice with platelet-specific defects in signaling by multiple GPCR receptors. A similar approach was used to eliminate function in both ITAM receptors expressed on the platelet surface. Platelets isolated from mice deficient in C-type lectin-2 were treated with inhibitors to GPVI, washed and infused into a different set of thrombocytopenic hIL4Ra/GPIba-tg mice [22]. Using this approach, we were able to show that platelet ITAM but not GPCR signaling is critical for vascular integrity at sites of inflammation [17].

\section{Conclusions}

There are several key advantages of this novel adoptive platelet transfer method over previously used approaches to inhibit specific platelet functions. First and foremost, it allows for the very rapid generation of mice with platelet-specific signaling defects, as induction of virtually complete thrombocytopenia and platelet transfusion into hIL4Ra/ GPIba-tg mice can be achieved within a few hours. In comparison, the generation of platelet-specific knockout mice requires many months. Second, the adoptive transfer system facilitates the combined use of genetic and pharmacologic approaches to loss of function studies. It is important to point out, however, that pharmacologic inhibition only works for compounds that irreversibly inhibit a specific signaling molecule, as reversible inhibitors would be washed out. Third, adoptive transfer allows us to set the peripheral platelet count in mice before challenge, thereby permitting a greater sensitivity for platelet defects. This is 
particularly important when few circulating platelets are sufficient to prevent a phenotype, such as shown for vascular integrity at sites of inflammation [5]. Without lowering the peripheral platelet count, it seems unlikely that a partial reduction in a critical platelet function would lead to a detectable phenotype. Lastly, it is well-documented that genetic deletion of genes can lead to the upregulation of compensatory mechanisms in mice [23]. In addition, as outlined above, even platelet-specific deletion of genes can lead to marked vascular changes as these cells control angiogenesis and vascular integrity during development $[24,25]$. The rapid replacement of endogenous platelets with donor platelets, achieved by adoptive transfer, eliminates both of these limitations. In summary, this novel method of adoptive platelet transfer provides a powerful means for deciphering the unique ways by which platelets contribute to health and disease.

\section{Acknowledgments}

The authors would like to acknowledge the collaboration with the laboratories of Jerry Ware, Nigel Mackman, and Mark Kahn on the project investigating the platelet signaling response important for vascular integrity in inflammation. This work was supported by the American Heart Association (12POST12040088) (Y.B.) and National Heart, Lung, and Blood Institute, NIH, grants R01 HL094594 and HL106009 (W.B.).

\section{References}

1. Nurden AT. Platelets, inflammation and tissue regeneration. Thromb Haemost. 2011; 105(Suppl 1):S13-S33. [PubMed: 21479340]

2. Semple JW, Italiano JE, Freedman J. Platelets and the immune continuum. Nat Rev Immunol. 2011; 11:264-274. [PubMed: 21436837]

3. Gasic GJ, Gasic TB, Stewart CC. Antimetastatic effects associated with platelet reduction. Proceedings of the National Academy of Sciences of the United States of America 1968th ed. 1968; 61:46-52.

4. Kisucka J, Butterfield CE, Duda DG, Eichenberger SC, Saffaripour S, Ware J, et al. Platelets and platelet adhesion support angiogenesis while preventing excessive hemorrhage. Proceedings of the National Academy of Sciences of the United States of America. 2006; 103:855-860. [PubMed: 16418262]

5. Goerge T, Ho-Tin-Noe B, Carbo C, Benarafa C, Remold-O'Donnell E, Zhao BQ, et al. Inflammation induces hemorrhage in thrombocytopenia. Blood. 2008; 111:4958-4964. [PubMed: 18256319]

6. Lo SK, Burhop KE, Kaplan JE, Malik AB. Role of platelets in maintenance of pulmonary vascular permeability to protein. The American journal of physiology. 1988; 254:H763-H771. [PubMed: 3354701]

7. Mahalingam M, Ugen KE, Kao KJ, Klein PA. Functional role of platelets in experimental metastasis studied with cloned murine fibrosarcoma cell variants. Cancer Res. 1988; 48:1460-1464. [PubMed: 3345518]

8. Nieswandt B, Hafner M, Echtenacher B, Mannel DN. Lysis of tumor cells by natural killer cells in mice is impeded by platelets. Cancer Res. 1999; 59:1295-1300. [PubMed: 10096562]

9. Tiedt R, Schomber T, Hao-Shen H, Skoda RC. Pf4-Cre transgenic mice allow the generation of lineage-restricted gene knockouts for studying megakaryocyte and platelet function in vivo. Blood. 2007; 109:1503-1506. [PubMed: 17032923]

10. Alexander WS, Roberts AW, Maurer AB, Nicola NA, Dunn AR, Metcalf D. Studies of the c-Mpl thrombopoietin receptor through gene disruption and activation. Stem Cells. 1996; 14(Suppl 1): 124-132. [PubMed: 11012212]

11. Shivdasani RA, Rosenblatt MF, Zucker-Franklin D, Jackson CW, Hunt P, Saris CJ, Orkin SH. Transcription factor NF-E2 is required for platelet formation independent of the actions of 
thrombopoietin/MGDF in megakaryocyte development. Cell. 1995; 81:695-704. [PubMed: 7774011]

12. Levin J, Peng JP, Baker GR, Villeval JL, Lecine P, Burstein SA, Shivdasani RA. Pathophysiology of thrombocytopenia and anemia in mice lacking transcription factor NF-E2. Blood. 1999; 94:3037-3047. [PubMed: 10556187]

13. Lesurtel M, Graf R, Aleil B, Walther DJ, Tian Y, Jochum W, et al. Platelet-derived serotonin mediates liver regeneration. Science. 2006; 312:104-107. [PubMed: 16601191]

14. Mason KD, Carpinelli MR, Fletcher JI, Collinge JE, Hilton AA, Ellis S, et al. Programmed Anuclear Cell Death Delimits Platelet Life Span. Cell. 2007; 128:1173-1186. [PubMed: 17382885]

15. Zhang H, Nimmer PM, Tahir SK, Chen J, Fryer RM, Hahn KR, et al. Bcl-2 family proteins are essential for platelet survival. Cell Death Differ. 2007; 14:943-951. [PubMed: 17205078]

16. van Delft MF, Wei AH, Mason KD, Vandenberg CJ, Chen L, Czabotar PE, et al. The BH3 mimetic ABT-737 targets selective Bcl-2 proteins and efficiently induces apoptosis via Bak/Bax if Mcl-1 is neutralized. Cancer Cell. 2006; 10:389-399. [PubMed: 17097561]

17. Boulaftali Y, Hess PR, Getz TM, Cholka A, Stolla M, Mackman N, et al. Platelet ITAM signaling is critical for vascular integrity in inflammation. J Clin Invest. 2013; 123:908-916. [PubMed: 23348738]

18. Nieswandt B, Echtenacher B, Wachs FP, Schroder J, Gessner JE, Schmidt RE, et al. Acute systemic reaction and lung alterations induced by an antiplatelet integrin gpIIb/IIIa antibody in mice. Blood. 1999; 94:684-693. [PubMed: 10397735]

19. Nieswandt B, Bergmeier W, Rackebrandt K, Gessner JE, Zirngibl H. Identification of critical antigen-specific mechanisms in the development of immune thrombocytopenic purpura in mice. Blood. 2000; 96:2520-2527. [PubMed: 11001906]

20. Nieswandt B, Bergmeier W, Schulte V, Takai T, Baumann U, Schmidt RE, et al. Targeting of platelet integrin alphaIIbbeta3 determines systemic reaction and bleeding in murine thrombocytopenia regulated by activating and inhibitory FcgammaR. International Immunology. 2003; 15:341-349. [PubMed: 12618478]

21. Kanaji T, Russell S, Ware J. Amelioration of the macrothrombocytopenia associated with the murine Bernard-Soulier syndrome. Blood. 2002; 100:2102-2107. [PubMed: 12200373]

22. Watson SP, Herbert JMJ, Pollitt AY. GPVI and CLEC-2 in hemostasis and vascular integrity. J Thromb Haemost. 2010; 8:1456-1467. [PubMed: 20345705]

23. Davis J, Maillet M, Miano JM, Molkentin JD. Lost in transgenesis: a user's guide for genetically manipulating the mouse in cardiac research. Circulation Research. 2012; 111:761-777. [PubMed: 22935533]

24. Bertozzi CC, Schmaier AA, Mericko P, Hess PR, Zou Z, Chen M, et al. Platelets regulate lymphatic vascular development through CLEC-2-SLP-76 signaling. Blood. 2010; 116:661-670. [PubMed: 20363774]

25. Finney BA, Schweighoffer E, Navarro-Núñez L, Bénézech C, Barone F, Hughes CE, et al. CLEC-2 and Syk in the megakaryocytic/platelet lineage are essential for development. Blood. 2012; 119:1747-1756. [PubMed: 22186994] 


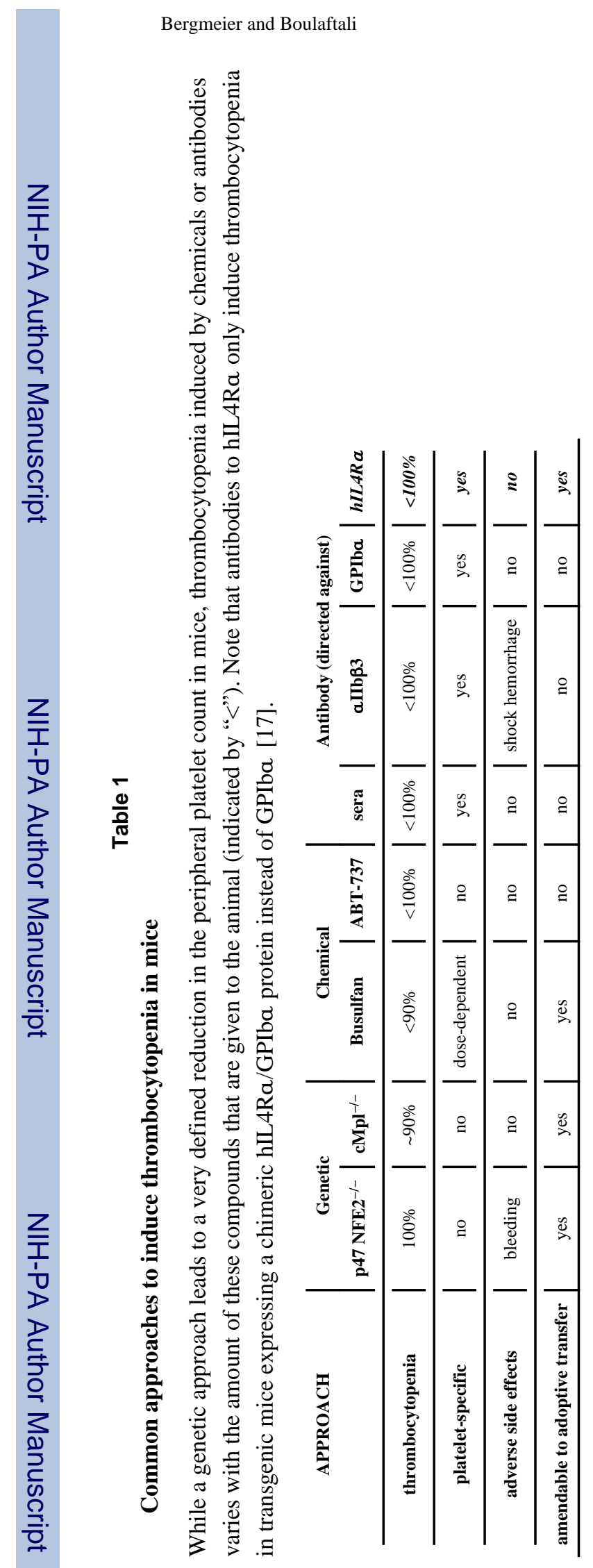

Thromb Res. Author manuscript; available in PMC 2015 May 01. 